\title{
Evaluation of Antimicrobial Effectiveness of Pimaricin-Loaded Thermosensitive Nanohydrogels in Grape Juice
}

\author{
Clara Fuciños • Pablo Fuciños • Paula Fajardo • \\ Isabel R. Amado • Lorenzo M. Pastrana • María L. Rúa
}

Received: 5 November 2014 / Accepted: 2 March 2015 /Published online: 15 March 2015

(C) Springer Science+Business Media New York 2015

\begin{abstract}
Pimaricin-loaded poly( $N$-isopropylacrylamide) nanohydrogels with and without acrylic acid, were evaluated as food-spoilage inhibitors in a model system and a real food product: grape juice. Pimaricin was proposed as a nonallergenic alternative to sulphites for protecting juices against recontamination. However, pimaricin may degrade under conditions and treatments (heating, acidification, lighting) commonly applied in producing fresh juices. Nanohydrogel encapsulation may be a feasible procedure to avoid pimaricin degradation, improving its antimicrobial activity. Pimaricinfree nanohydrogels did not affect the growth of the indicator yeast either in the food model system or in grape juice. Conversely, pimaricin-loaded nanohydrogels effectively inhibited the growth of the indicator yeast. In some cases, the inhibition was extended even further than using free pimaricin. For instance, in the food model system, pimaricin-loaded nanohydrogels with acrylic acid $\left(\mathrm{NP}_{\mathrm{PNIPA}-20 \mathrm{AA}(5)}\right)$ prevented the yeast growth for more than $81 \mathrm{~h}$ while free pimaricin was only effective for $12 \mathrm{~h}$. Despite pimaricin-loaded nanohydrogels without acrylic acid $\left(\mathrm{NP}_{\mathrm{PNIPA}(5)}\right)$ were able to reduce maximum yeast growth, as in all treatments with
\end{abstract}

C. Fuciños • P. Fuciños • I. R. Amado • L. M. Pastrana • M. L. Rúa

Biotechnology Group, Department of Analytical Chemistry and

Food Science, University of Vigo, As Lagoas s/n 32004,

Ourense, Spain

C. Fuciños ( $\square)$

Centre of Biological Engineering, University of Minho, Campus de Gualtar, 4710-057 Braga, Portugal

e-mail: clarafg@gmail.com

\section{P. Fuciños}

International Iberian Nanotechnology Laboratory (INL), Av. Mestre

José Veiga, 4715-330 Braga, Portugal

P. Fajardo

ANFACO-CECOPESCA, Colegio Universitario 16,

36310 Vigo, Pontevedra, Spain pimaricin, the extent of the inhibitory effect was not significantly $(p>0.05)$ different to that achieved with free pimaricin. In grape juice, both free pimaricin and $\mathrm{NP}_{\mathrm{PNIPA}-20 \mathrm{AA}(5)}$ treatment completely inhibited the growth of the indicator yeast until the end of the bioassay. However, the latter provided similar inhibition levels using a smaller amount of pimaricin due to PNIPA-20AA(5) protection and its controlled release from the nanohydrogel. Therefore, nanohydrogel encapsulation may help to optimise antifungal treatments and decrease the incidence of food allergies.

Keywords Smart packaging - Controlled release . Poly( $N$-isopropylacrylamide) nanohydrogels · Grape juice . Natamycin · Antimicrobial efficiency $\cdot$ Growth modelling

\section{Nomenclature}

$A$ and $B$

$A_{0}$

AA

C

$\mathrm{D}$

$F_{\text {min }}$

$F_{t}$

$I C_{50}$

Isopar $^{\mathrm{TM}} \mathrm{M}$

$k$

K

LCST

NIPA
Maximum growth of the indicator microorganism (expressed as OD) Initial growth of the indicator microorganism (expressed as OD). Acrylic acid Samples without any treatment Dose of pimaricin $\left(\mu \mathrm{g} \mathrm{mL}^{-1}\right)$ The minimal residual fraction of pimaricin achievable in different matrices during pimaricin degradation study Fraction of pimaricin Half maximal inhibitory concentration $\left(\mu \mathrm{g} \mathrm{mL} \mathrm{m}^{-1}\right)$

Isoparaffinic synthetic hydrocarbon The pimaricin degradation rate $\left(\mathrm{h}^{-1}\right)$ Real maximum response (maximum latency, h) Lower critical solution temperature $\mathrm{N}$-isopropylacrylamide 


\begin{tabular}{|c|c|}
\hline \multirow{3}{*}{$\begin{array}{l}\text { NMBA } \\
N_{\text {PNIPA-20AA(5) }}\end{array}$} & $N, N^{\prime}$-methylenebisacrylamide \\
\hline & Antimicrobial treatment with \\
\hline & $\begin{array}{l}\text { PNIPA-20AA(5) nanohydrogel } \\
\text { suspension without pimaricin }\end{array}$ \\
\hline \multirow[t]{2}{*}{$N_{\mathrm{PNIPA}(5)}$} & Antimicrobial treatment with \\
\hline & $\begin{array}{l}\text { PNIPA(5) nanohydrogel suspension } \\
\text { without pimaricin }\end{array}$ \\
\hline \multirow[t]{2}{*}{$\mathrm{NP}_{\mathrm{PNIPA}-20 \mathrm{AA}(5)}$} & Antimicrobial treatment with \\
\hline & $\begin{array}{l}\text { PNIPA-20AA(5) nanohydrogel } \\
\text { suspension loaded with pimaricin }\end{array}$ \\
\hline \multirow{2}{*}{$\mathrm{NP}_{\mathrm{PNIPA}(5)}$} & Antimicrobial treatment with \\
\hline & $\begin{array}{l}\text { PNIPA(5) nanohydrogel suspension } \\
\text { loaded with pimaricin }\end{array}$ \\
\hline OD & Optical density \\
\hline $\mathrm{P}$ & $\begin{array}{l}\text { Samples treated with a free } \\
\text { pimaricin solution }\end{array}$ \\
\hline PNIPA-20AA(5) & $\begin{array}{l}\text { Poly }(N \text {-isopropylacrylamide }) \\
\text { nanohydrogel copolymerized with } \\
\text { a } 20 \%(w / w) \text { of acrylic acid using } \\
5 \%(w / w) \text { of cross-linking }\end{array}$ \\
\hline PNIPA & $\operatorname{Poly}(N$-isopropylacrylamide) \\
\hline $\operatorname{PNIPA}(5)$ & $\begin{array}{l}\text { Poly }(N \text {-isopropylacrylamide }) \\
\text { nanohydrogel with } 5 \%(w / w) \\
\text { of cross-linking }\end{array}$ \\
\hline PNIPA/AA & $\begin{array}{l}\text { Poly }(N \text {-isopropylacrylamide }) \\
\text { nanohydrogel with or without } \\
\text { copolymerized acrylic acid }\end{array}$ \\
\hline RP-HPLC & $\begin{array}{l}\text { Reverse-phase high-performance } \\
\text { liquid chromatography }\end{array}$ \\
\hline S.D. & Standard diluent solution \\
\hline $\operatorname{Span}^{\mathrm{TM}} 83$ & Sorbitan sesquiolate \\
\hline$v_{\max }$ & Maximum growth rate $\left(\mathrm{h}^{-1}\right)$ \\
\hline YPD broth & $\begin{array}{l}\text { Yeast extract at } 15 \mathrm{~g} \mathrm{~L}^{-1} \text {, peptone } \\
\text { at } 20 \mathrm{~g} \mathrm{~L}^{-1} \text { and glucose at } 20 \mathrm{~g} \mathrm{~L}^{-1} \\
\text { dissolved in distilled water and } \\
\text { sterilised }\end{array}$ \\
\hline$\lambda$ & Time of latency (h) \\
\hline
\end{tabular}

\section{Introduction}

The global food packaging industry has a good deal to contribute not only in addressing food losses but also in ensuring food safety, as well as enhancing global food trade, which is a key to the economic development of varying economies. If there is an industry sector that is equally, if not more, dynamic than the food sector, it is none other than the packaging industry. Food accounts for $50 \%$ of the global consumer packaging industry, valued at US\$ 380 billion as of 2009. If the beverage sector is to be added, that will even increase to $69 \%$ (Manalili et al. 2011). The continued quest for innovation in food and beverage packaging is mostly driven by consumer needs and demands influenced by changing global trends, such as increased life expectancy, fewer organisations investing in food production and distribution, and regionally abundant and diverse food supply (Brody et al. 2008). All this combined with the interest of consumers for healthy eating and its active lifestyles is the key to the success of the ready-to-eat food products like fresh fruit juices. However, the stability of these products is compromised due to contamination by moulds and yeasts, which involve a serious preservation problem. Standard thermal treatments do not allow for maintaining the organoleptic characteristics of the product and chemical preservatives, such as sulphites, which may cause allergy problems (Vally and Misso 2012). Therefore, natural preservatives such as pimaricin can be a valuable alternative.

Pimaricin (natamycin) is a polyene macrolide fungicide produced by submerged aerobic fermentation of Streptomyces natalensis and related species (Farid et al. 2000; Vanden Bossche et al. 2003). It is widely used in food industry as a preservative on the surface of cheese, fruits and other nonsterile products, such as meat and sausages (Stark and Tan 2003). Pimaricin has several advantages as food preservative: it is non-toxic; it has no influence on taste or appearance; it has a favourable consumer perception because it is a natural ingredient (contrary to chemical preservatives); it is active in low concentrations; and it has no antibacterial activity so the natural ripening process in fermented products is not influenced (Stark and Tan 2003). Nevertheless, some important technological disadvantages that limit its food applications are indicated: pimaricin has a low solubility that limits its use to surface treatments applications, and the chemical stability in acidic conditions and under light radiation is low (Koontz et al. 2003; Stark and Tan 2003). This explains why, although the initial microbial load in a processed food is usually low, food preservatives are directly added at a high concentration when manufactured keeping an effective concentration during storage. However, preservative concentrations could be reduced (and, consequently, its intake by consumers) maintaining suitable levels of food safety by using the delivery system as proposed by active packaging technologies.

Traditional packaging protects food from external influences, such as microorganisms, oxygen, off-odours, light etc. and, by doing so, guarantees convenience in food handling and preserves the food quality for an extended time period. The key safety objective for these traditional materials in contact with foods is to be as inert as possible, i.e. there should be a minimum interaction between food and packaging (Dainelli et al. 2008). In recent years, however, one of the most innovative developments in the area of food packaging is active and smart packaging based on the interaction of packages with food and environment and playing a dynamic role in food preservation (Brody et al. 2008; Dainelli et al. 2008). Smart packaging responds to environmental conditions 
by improving food protection (e.g. by antimicrobial release) or alerting consumers of contamination and/or the presence of pathogens (Sekhon 2010). In active and smart packaging, nanotechnology has a great potential because nanostructures display a high surface-to-volume ratio and specific surface properties. Recent studies also show that nanoparticles can be tailored for both controlled release and/or specificity in the action of the active agent, with moisture or temperature as triggering mechanisms (Dainelli et al. 2008).

Nanohydrogels of poly ( $N$-isopropylacrylamide) (PNIPA) are cross-linked polymeric networks from 10 to $1000 \mathrm{~nm}$ swollen by a good solvent. Since they are biocompatible and non-toxic, they are commonly used as carriers or delivery devices in anticancer applications and suitable for food use. PNIPA nanohydrogels are thermosensitive with a lower critical solution temperature (LCST) of around $33^{\circ} \mathrm{C}$. Above the LCST, hydrophobic interactions within polymer chains are dramatically strengthened, leading to the abrupt collapse of the polymer chains and the phase transition of the gel network (Zhang et al. 2002). The nanohydrogel collapse pattern can be easily modulated varying the polymer composition by introducing different functional groups and so the release behaviour can change, allowing for a precise controlled delivery of the loaded active agent (Eeckman et al. 2004). Thus, copolymerization of acrylic acid (AA) into PNIPA nanohydrogels results in nanohydrogels with more subtle temperature transition (Fuciños et al. 2014a, b). This behaviour helps pimaricin release from inside the polymer matrix, since AA provides more hydrated shrunken states that favour a sustained pimaricin release (Fuciños et al. 2014b).

The ability of PNIPA nanohydrogels copolymerized with AA to transport and release pimaricin as a response of environmental triggers such as temperature and $\mathrm{pH}$ was demonstrated (Fuciños et al. 2012, 2014b). Additionally, in the work of Fuciños et al. (2012), it was demonstrated that pimaricin antimicrobial activity in a solid food model system was potentiated when it was loaded into the PNIPA-20AA(5) nanohydrogel, due to the protective effect of nanohydrogel against external conditions ( $\mathrm{pH}$, light) that harmed pimaricin. However, to the best of our knowledge, there has been no work about the use of smart active packaging based on PNIPA nanohydrogels to control the microbial spoilage in real food. Therefore, the main objective of this work was to investigate the effectiveness of these systems in controlling spoilage due to microbial growth in a liquid food model system and in fresh grape juice.

\section{Materials and Methods}

Materials

Commercial pimaricin (50\% pure pimaricin, $50 \%$ lactose) was obtained from VGP Pharmachem (Barcelona, Spain).
Pure pimaricin $\left(M=665.73 \mathrm{~g} \mathrm{~mol}^{-1}\right)$ from Streptomyces chattanoogensis ( $\geq 95 \%$, high-performance liquid chromatography (HPLC)) was supplied by Sigma-Aldrich (Munich, Germany). Dialysis bags (SnakeSkin ${ }^{\mathrm{TM}}$ pleated dialysis tubing), with a molar mass cut-off of $3500 \mathrm{~g} \mathrm{~mol}^{-1}$, were supplied by Pierce (Rockford, IL, USA).

NIPA (99\%) from Acros Organics (Geel, Belgium), acrylic acid (AA; stabilised with hydroquinone monomethyl ether) for synthesis, $N, N^{\prime}$-methylenebisacrylamide (NMBA) for synthesis and sodium bisulfite $\left(\mathrm{NaHSO}_{3}\right)$ for analysis were supplied by Merck (Darmstadt, Germany); isoparaffinic synthetic hydrocarbon (Isopar ${ }^{\mathrm{TM}} \mathrm{M}, 98 \%$ ) was kindly supplied by Quimidroga, S.A. (Barcelona, Spain); sorbitan sesquiolate (Span ${ }^{\mathrm{TM}}$ 83, $98 \%$ ) and PEG-40 sorbitol hexaoleate (Atlas ${ }^{\mathrm{TM}}$ G-1086, 98 \%) were kindly supplied by Croda Ibérica, S.A. (Barcelona, Spain); and chloroform and diethyl ether were from Panreac (Barcelona, Spain).

Saccharomyces cerevisiae strain was obtained from Colección Española de Cultivos Tipo (CECT; Spain). The $\mathrm{D}(+)$-glucose anhydrous PA-ACS, bacteriological peptone and yeast extract were all obtained from Panreac (Barcelona, Spain). Acetic acid puriss. p.a. ACS reagent $(\geq 99.8 \%)$ and methanol CHROMASOLV ${ }^{\circledR}$ for HPLC $(\geq 99.9 \%)$ were obtained from Sigma-Aldrich (Munich, Germany). Commercial white grape juice was used as received.

\section{Pimaricin Detection by Reverse Phase High-Performance Liquid Chromatography}

Pimaricin quantification by reverse-phase high-performance liquid chromatography (RP-HPLC) was performed following a modified method from Roberts et al. (2011), using an Agilent 1200 system equipped with a Variable Wavelength Detector (Agilent Technologies, Palo Alto, CA, USA). Separation was performed employing an $\mathrm{ACE}^{\circledR} \mathrm{C} 18$ column (4.6× $150 \mathrm{~mm}, 5 \mu \mathrm{m}$ ) with the column oven kept at $30^{\circ} \mathrm{C}$. The flow rate was $1.0 \mathrm{~mL} \mathrm{~min}^{-1}$, the injection volume was $20 \mu \mathrm{L}$ and the detection wavelength was $319 \mathrm{~nm}$. Mobile phase A consisted in MilliQ water/acetic acid $(97: 3, v / v)$ and mobile phase B consisted in methanol/acetic acid (97:3, v/v). Mobile phase A was maintained at $90 \%$ for the first $6 \mathrm{~min}$, and then decreased linearly to $10 \%$ over $25 \mathrm{~min}$. Finally, mobile phase A was increased to $90 \%$ and the column was re-equilibrated for a further $9 \mathrm{~min}$.

The assay response was highly linear (Fig. 1) within the concentration range 0.05 to $10 \mu \mathrm{g} \mathrm{mL}^{-1}$ of pure pimaricin dissolved in a methanol/MilliQ water/acetic acid solution (50:47:3, v/v/v; standard diluent solution (S.D.)).

The accuracy of pimaricin quantification by RP-HPLC was determined by adding, in duplicate, pure pimaricin to culture broth and grape juice to obtain final concentrations of $5 \mu \mathrm{g} \mathrm{mL}^{-1}$. Figure 2 shows an HPLC chromatogram at $319 \mathrm{~nm}$ of S.D., culture broth and grape juice added with the 


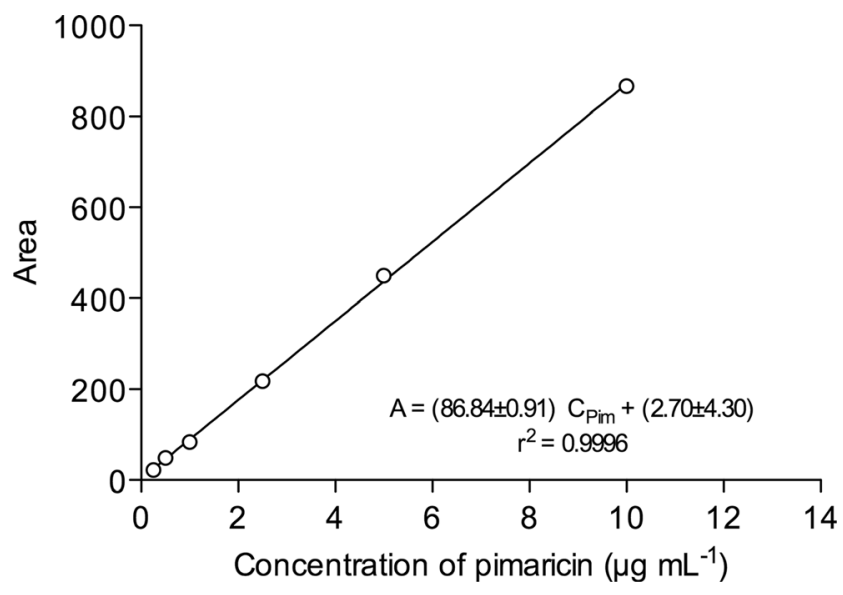

Fig. 1 Pimaricin standard curve prepared in a standard diluent solution (S.D.) for quantification by RP-HPLC

same amount of pimaricin. The recovery was very high: $98.11 \%$ for the culture broth and $97.32 \%$ for the grape juice. Therefore, it was possible to avoid pimaricin extraction from the matrices evaluated in this work before its detection by HPLC.

\section{Pimaricin Stability in Different Matrices}

Pimaricin degradation was evaluated in two different matrices: culture broth and grape juice. The culture broth was YPD (yeast extract, $15 \mathrm{~g} \mathrm{~L}^{-1}$; peptone, $20 \mathrm{~g} \mathrm{~L}^{-1}$; glucose, $20 \mathrm{~g} \mathrm{~L}^{-1}$ ). Both matrices, YPD broth and grape juice, were added with an aqueous solution of commercial pimaricin $\left(4 \mu \mathrm{g} \mathrm{mL}^{-1}\right)$ and stored at 37 and $25^{\circ} \mathrm{C}$, respectively. The pimaricin concentration was monitored daily over 15 days by RP-HPLC.

Pimaricin degradation in grape juice was also evaluated under pasteurisation conditions. For this purpose grape juice was added with an aqueous solution of commercial pimaricin

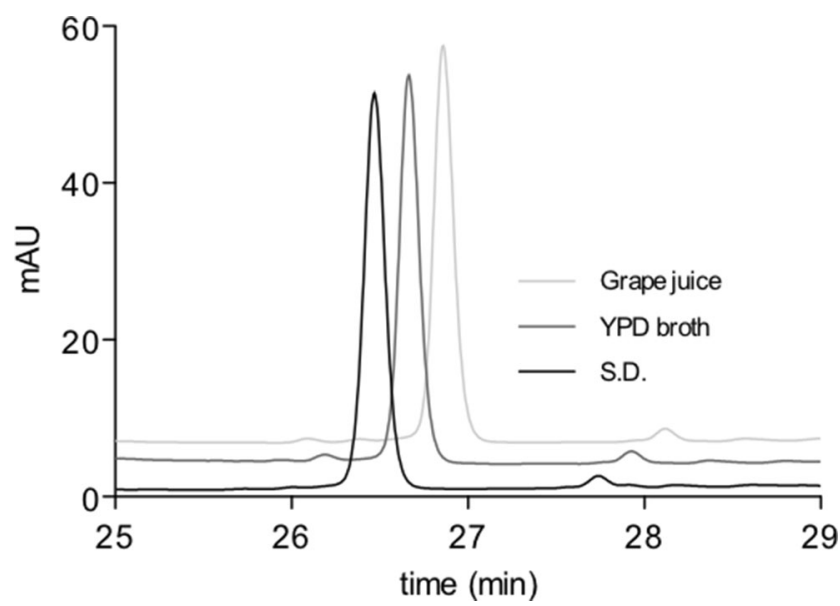

Fig. 2 HPLC chromatogram at $319 \mathrm{~nm}$ of standard diluent solution (S.D.), YPD broth and grape juice, all added with pure pimaricin $\left(5 \mu \mathrm{g} \mathrm{mL}^{-1}\right)$ $\left(3 \mu \mathrm{g} \mathrm{mL} L^{-1}\right)$ and heated at $80{ }^{\circ} \mathrm{C}$ in a thermostatic bath. Aliquots were removed at different time intervals (as short as possible to obtain a smooth shape curve) within $1 \mathrm{~h}$, and the pimaricin concentration was also determined by RP-HPLC. All the experiments were carried out in duplicate.

In order to standardise the results, the fraction of pimaricin at each sampling time was calculated as follows:

$F_{t}=1-\frac{C_{0}-C_{t}}{C_{0}}$

where $C_{t}$ and $C_{0}$ are the pimaricin concentration $\left(\mu \mathrm{g} \mathrm{mL}^{-1}\right)$ at time $t$ and at the initial time, respectively.

Pimaricin remaining fraction at each time $\left(F_{t}\right)$, standardised according to Eq. 1, were fitted with the following equation:

$F_{t}=\left(F_{0}-F_{\min }\right) e^{-k \cdot t}+F_{\min }$

where $F_{0}$ is the initial fraction of pimaricin, $F_{t}$ is the remaining fraction of pimaricin at time $t, F_{\min }$ is the minimal residual fraction of pimaricin achievable in the different matrices, $k$ is the pimaricin degradation rate $\left(\mathrm{h}^{-1}\right)$, and $t$ is the sampling time (h). The pimaricin half-life (h) can be calculated as $\frac{\ln 2}{k}$.

\section{Antimicrobial Activity}

\section{Preparation of Pimaricin-Loaded Nanohydrogel}

The synthesis method for PNIPA(5) and PNIPA-20AA(5) were as reported in Fuciños et al. (2012). For pure PNIPA nanohydrogels (PNIPA(5)), the ratio of NIPA based on the monomers $\left(m_{\mathrm{NIPA}} / m_{\text {monomer }}\right)$ was 1 . For NIPA copolymerized with AA (PNIPA-20AA(5)) nanohydrogels $m_{\mathrm{NIPA}} / m_{\text {monomer }}$ was 0.80 and $m_{\mathrm{AA}} / m_{\text {monomer }}$ was 0.20 . Atlas ${ }^{\mathrm{TM}} \mathrm{G}-1086$ and Span $^{\mathrm{TM}} 83$ were used as surfactants dissolved in Isopar ${ }^{\mathrm{TM}}$ and NMBA was used as cross-linking agent at a ratio $m_{\mathrm{NMBA}} / m_{\text {monomer }}=0.05$. Polymerisation initiator was $\mathrm{NaHSO}_{3}$ at a ratio $m_{\mathrm{NaHSO} 3} / m_{\text {monomer }}=0.01$ and chloroform and diethyl ether were used to selectively purify synthesised nanoparticles.

The method to prepare pimaricin-loaded nanohydrogels was as reported in Fuciños et al. (2012), with some modifications. During the inhibition studies, YPD broth-replaced distilled water avoid broth dilution of the growing broth with water during the subsequent dialysis process. PNIPA/AA nanohydrogel powder was dispersed in a sterile YPD broth by agitation using a magnetic stirrer during $3 \mathrm{~h}$ at ambient temperature to allow the nanoparticles to swell. Then, this suspension was mixed with a pimaricin solution in sterile YPD broth to obtain final concentrations of $12.5 \mathrm{mg}$ of nanohydrogel per milliliter and $0.4 \mathrm{mg}$ of commercial pimaricin powder per milliliter $\left(21.93 \mu \mathrm{g} \mathrm{mL}^{-1}\right.$ of solubilised 
pure pimaricin). The mixture was stirred overnight at $25{ }^{\circ} \mathrm{C}$ (below LCST) to guarantee pimaricin incorporation into the nanohydrogel. Nanohydrogel samples without pimaricin and free pimaricin samples were processed under the same conditions as above.

For the inhibition studies employing grape juice only, PNIP A-20AA(5) nanohydrogel was used. Samples of the nanohydrogel loaded with pimaricin, the nanohydrogel without pimaricin and free pimaricin were prepared as explained above, except that YPD broth was replaced with white grape juice. The $\mathrm{pH}$ of the grape juice employed at this point was increased to 8 during the loading step to guarantee the correct swelling of the nanohydrogel because PNIPA-20AA(5) collapses at the $\mathrm{pH}$ of the grape juice (3.5), as was seen in Fuciños et al. (2014a). The experiments were carried out in duplicate, under sterile conditions.

\section{Preparation of Indicator Microorganism Suspension}

In order to force spoilage in both food model system and real food, $S$. cerevisiae was chosen as indicator microorganism because, between the most commonly known spoilage yeast, $S$. cerevisiae presents widely studied a physiological, biochemical and genetic responses (Ollé Resa et al. 2014).

The 12-h culture of the indicator microorganism $(6 \times$ $10^{7} \mathrm{CFU} \mathrm{mL} \mathrm{m}^{-1}$ ) was prepared, in duplicate, with a stock culture of $S$. cerevisiae previously grown in YPD broth during two consecutive precultures of $12 \mathrm{~h}$ each, to ensure that most of the yeast cells were viable. For the inhibition studies in grape juice, a second 12-h culture was performed inoculating, in duplicate, grape juice ( $\mathrm{pH} 3.5)$ with a 12-h culture growth in YPD broth in a first step.

\section{Dose-Response Assessment of Pimaricin: $I C_{50}$}

Dose-response assay was performed in two different matrices: YPD broth and grape juice. Both matrices were inoculated with the indicator microorganism prepared as explained in Sect. 2.4.2. Their final optical density (OD) at $600 \mathrm{~nm}$ was adjusted to 0.010 ( $1 \mathrm{~mm}$ path length). The required volume of pimaricin stock solution, prepared under sterile conditions, was added to each matrix to obtain final pimaricin concentrations ranging from 0 to $10 \mu \mathrm{g} \mathrm{mL}^{-1}$. They were then incubated at $37{ }^{\circ} \mathrm{C}$ for the culture broth and $25^{\circ} \mathrm{C}$ for the grape juice, under agitation at $120 \mathrm{rpm}$. At selected times, aliquots of $1 \mathrm{~mL}$ were removed, in duplicate, to monitor the $S$. cerevisiae growth spectophotometrically (Beckman Coulter Inc., Brea, CA, USA) at $600 \mathrm{~nm}$. The obtained OD values were fitted with Eq. 5, and the time of latency $(\lambda)$ obtained from this equation was used as a response of $S$. cerevisiae growth to increasing concentrations (doses) of pimaricin.

The half maximal inhibitory concentration $\left(\mathrm{IC}_{50} ; \mu \mathrm{g} \mathrm{mL}{ }^{-1}\right)$ of pimaricin in both matrices, YPD broth and grape juice, was calculated by fitting the dose-response data to Weibull's equation, reparameterised to make the $\mathrm{IC}_{50}$ explicit as proposed in Murado et al. (2002):

$\lambda_{D}=K\left(1-e^{-\ln 2\left(\frac{D}{\mathrm{I}_{50}}\right)^{\alpha}}\right)$

where $\lambda_{D}$ is the latency (h) of the indicator microorganism obtained as a response to the exposure to different doses of pimaricin $\left(D ; \mu \mathrm{g} \mathrm{mL}^{-1}\right) . K$ is the real maximum response (maximum latency, $\mathrm{h}$ ) and $\alpha$ is a shape parameter related to the maximum slope of the response.

\section{Antimicrobial Activity of Pimaricin-Loaded PNIPA/AA Nanohydrogels}

The following antimicrobial devices, obtained as explained in Section 2.4.1, were tested: PNIPA(5) nanohydrogel suspension without pimaricin $\left(N_{\mathrm{PNIPA}(5)}\right)$, PNIPA(5) nanohydrogel suspension loaded with pimaricin $\left(\mathrm{NP}_{\mathrm{PNIPA}(5)}\right)$, PNIPA-20AA(5) nanohydrogel suspension without pimaricin $\left(N_{\mathrm{PNIPA}-20 \mathrm{AA}(5)}\right)$, PNIPA-20AA(5) nanohydrogel suspension loaded with pimaricin $\left(\mathrm{NP}_{\mathrm{PNIPA}-20 \mathrm{AA}(5)}\right)$, free pimaricin solution $(P)$. Culture samples without any treatment $(C)$ were processed simultaneously under the same conditions. Three milliliters from each system were placed in a dialysis bag and dialyzed against $12 \mathrm{~mL}$ of the YPD broth or grape juice, inoculated with the indicator microorganism prepared as explained in Sect. 2.4.2. Their final OD at $600 \mathrm{~nm}$ were adjusted to 0.020 and 0.010 (1 mm path length) in the experiments with YPD broth and grape juice, respectively. The incubation temperature was $37^{\circ} \mathrm{C}$ for the bioassay in culture broth. The bioassay in grape juice was kept at $8{ }^{\circ} \mathrm{C}$ for $6 \mathrm{~h}$ and then the temperature was raised to $25{ }^{\circ} \mathrm{C}$, until the end of the experiment. The experiments were carried out in duplicate under sterile conditions.

To monitor the $S$. cerevisiae growth, $2-\mu \mathrm{L}$ aliquots were removed from the dialysate at selected times and their OD measured at $600 \mathrm{~nm}$ using a Thermo Scientific NanoDrop 2000c (Wilmington, DE, USA). Low volume samples were taken in order to be able to assume a constant dialysis volume, because sterile conditions did not allow for sample replacement.

Specific inhibition was calculated as follows:

$\%$ Inhibition $=\frac{\mathrm{OD}_{0}-\mathrm{OD}}{\mathrm{OD}_{0}} ;$ Specific inhibition $=\frac{\% \text { Inhibition }}{C_{t}}$

where, $\mathrm{OD}_{0}$ is the optical density of the samples in the treatments without pimaricin ( $C$ and $\left.N_{\text {PNIPA-20AA(5) }}\right)$ and OD is the optical density of samples with pimaricin $\left(P\right.$ and $\left.\mathrm{NP}_{\mathrm{PNIPA}-20 \mathrm{AA}(5)}\right)$. $C_{t}$ is the pimaricin concentration $\left(\mu \mathrm{g} \mathrm{mL}^{-1}\right)$ at each sampling time. 


\section{Growth Modelling}

The logistic equation is widely used to describe and predict the microbial growth inhibition (Zwietering et al. 1990; Bozkurt and Erkmen 2001; Wachenheim et al. 2003; Vázquez et al. 2008; Vázquez and Murado 2008). Nevertheless, the traditional formal description of the logistic equation presents some drawbacks when it comes to performing statistical comparisons on treatments with microbial growth inhibitors. In addition to maximum growth, another valuable parameter for comparative studies is the lag period. However, this parameter is not explicit in the logistic equation. Therefore, to describe parameters with such a relevant biological meaning, the logistic equation should be reparameterised (Zwietering et al. 1990; Vázquez et al. 2008):

$$
\mathrm{OD}_{t}=\frac{B}{1+e^{2+\frac{4 \cdot v_{\max } B}{B}}\left(\lambda_{B}-t\right)}
$$

where $B$ is the maximum growth of the microorganism (expressed as OD), $v_{\max B}$ is the maximum growth rate $\left(\mathrm{h}^{-1}\right)$, and $\lambda_{B}$ and $t$ are the latency and the sampling time, respectively, both expressed in hours. However, this equation is only useful for fitting microbial growth data in a single phase. Previous works have attempted to model two-phase microbial growth (Guerra et al. 2010) by just summing two simple logistic functions. Nevertheless, this approach fails to provide an explicit parameter to describe the actual maximum growth in the second phase, which does not coincide with the asymptote of the second logistic. In this work, a new reparameterised form of a bilogistic function is proposed:

$$
\begin{aligned}
\mathrm{OD}_{t}= & \frac{A}{1+\left(\frac{A}{A_{0}}-1\right) e^{-\frac{4 \cdot v_{\max } \cdot t}{A}}} \\
& +\frac{B-A}{1+e^{\frac{2\left(B+A+2 \cdot \lambda_{B} \cdot v_{\max B}\right)}{B-\frac{4 \cdot v_{\max } \cdot t}{B-A}}}}
\end{aligned}
$$

where the first part of the model is a reparameterised logistic function, commonly used in the literature to fit microorganism growth or inactivation (Dalgaard and Koutsoumanis 2001; Wachenheim et al. 2003; Dai et al. 2010), allowing us to predict the antifungal effect on the first growth phase. $A_{0}$ and $A$ are, respectively, the initial and maximum growth of the indicator microorganism (expressed as OD) in the first step. $v_{\max A}$ is the maximum growth rate $\left(\mathrm{h}^{-1}\right)$ for this phase in the presence of the inhibitor, and $t(\mathrm{~h})$ is the sampling time. The second part of the model corresponds to a logistic equation reparameterised to explicitly show the maximum growth $\left(B\right.$, expressed as OD) and the latency of the second phase $\left(\lambda_{B}\right.$, $h)$ that in this case, refers to the regeneration time required for the yeast to repair the membrane damage caused by pimaricin (Te Welscher et al. 2008), in the first phase. $v_{\max B}$ is the maximum growth rate $\left(\mathrm{h}^{-1}\right)$ for the second phase.

Data Fitting and Statistical Analysis

The antimicrobial effectiveness amongst treatments was evaluated with analysis of variance (one-way ANOVA) followed by Bonferroni posttests for multiple comparisons using GraphPad Prism $^{\text {TM }} 5$ (GraphPad Software Inc., San Diego, CA, USA).

Plotting and data fitting were performed with GraphPad Prism $^{\mathrm{TM}} 5$ (GraphPad Software Inc., San Diego, CA, USA). The significance of the model parameters were assessed using SigmaPlot version 11.0 from Systat Software, Inc. (San Jose, CA, USA).

\section{Results and Discussion}

\section{Pimaricin Stability in Different Matrices}

Degradation kinetics were performed to calculate the half-life of pimaricin in the two matrices assayed (YPD broth and grape juice). The results of monitoring the pimaricin degradation are illustrated in Fig. 3. Table 1 summarises the best-fit parameters obtained for Eq. 2. At low temperatures $\left(<37^{\circ} \mathrm{C}\right)$, the $\mathrm{pH}$ effect prevailed over the temperature effect. Despite performing the grape juice assay at a temperature $12{ }^{\circ} \mathrm{C}$ lower than the YPD broth assay, the rate of pimaricin degradation $(k)$ in grape juice was 2-fold higher ( $p=0.0091)$ than that observed in the culture broth. This behaviour may be caused by the acidic conditions of grape juice ( $\mathrm{pH} 3.5$ ), in which pimaricin may be rapidly degraded, producing mycosamine by hydrolysis of the glycosidic bond

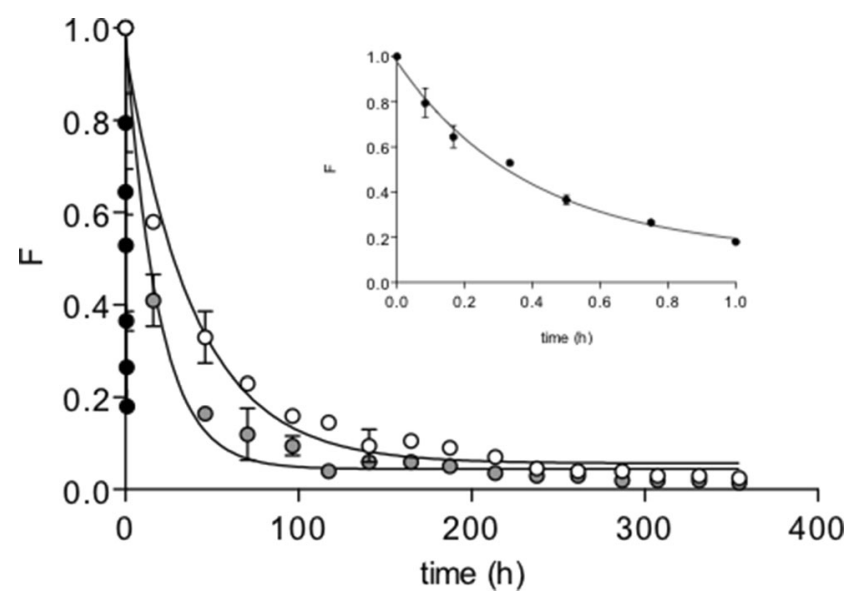

Fig. 3 Variation of remaining pimaricin fraction $(F)$, standardised according to Eq. 1, in YPD broth at $37{ }^{\circ} \mathrm{C}$ (white-filled circles) and grape juice at $25^{\circ} \mathrm{C}$ (grey-filled circles) and $80^{\circ} \mathrm{C}$ (black-filled circle). The graph inset is an enlarged representation of the data in the $80{ }^{\circ} \mathrm{C}$ series. The lines are the fitting curves generated from Eq. $2\left(r^{2}\right.$ YPD broth $\left(37^{\circ} \mathrm{C}\right)=0.9813 ; r^{2}$ grape juice $\left(25^{\circ} \mathrm{C}\right)=0.9839 ; r^{2}$ grape juice $\left.\left(80{ }^{\circ} \mathrm{C}\right)=0.9850\right)$ 
Table 1 Pimaricin degradation parameters in different matrices and temperatures calculated with Eq. 2

\begin{tabular}{cllll}
\hline Matrices & $T\left({ }^{\circ} \mathrm{C}\right)$ & $F_{\min }$ & $k\left(\mathrm{~h}^{-1}\right)$ & Half-life $(\mathrm{h})$ \\
\hline $\begin{array}{c}\text { YPD } \\
\text { broth }\end{array}$ & 37 & $0.057 \pm 0.009^{* * *}$ & $0.025 \pm 0.002^{* * * *}$ & $27.29 \pm 1.697 * * *$ \\
$\begin{array}{c}\text { Grape } \\
\text { juice }\end{array}$ & 25 & $0.044 \pm 0.006^{* * *}$ & $0.053 \pm 0.003^{* * *}$ & $13.05 \pm 0.807^{* * *}$ \\
& 80 & $0.129 \pm 0.043^{\text {n.s. }}$ & $2.551 \pm 0.339^{* *}$ & $0.272 \pm 0.036^{* *}$ \\
\hline
\end{tabular}

Values reported are the means \pm standard deviation $(n=2)$

$n . s$. not significant $(p>0.05)$

${ }^{*} p<0.05$, significant; ${ }^{* *} p<0.01$, very significant; ${ }^{* * *} p<0.001$, extremely significant

(Koontz et al. 2003). With respect to the $F_{\min }$ value, there are no significant differences $(p=0.2393)$ between the culture broth and grape juice. Despite the low temperature, in the long run $(t>250 \mathrm{~h})$ pimaricin was completely degraded in both cases.

The calculated half-lives (Table 1) were $27 \mathrm{~h}$ in YPD broth, and $13 \mathrm{~h}$ in grape juice. Pedersen (1992) has reported pimaricin losses of $34 \%$ at $50{ }^{\circ} \mathrm{C}$ during the preparation of YPD plates, and the half-life of pimaricin in YPD plates stored at $6{ }^{\circ} \mathrm{C}$ under dark conditions was 31 days. In our case (at lower temperatures), regardless of whether the media was acidic or not, the pimaricin half-life was notably lower, probably because our assays were performed under light radiation where its chemical stability has been reported to be low (Stark and Tan 2003; Koontz et al. 2003). The same applies when comparing the calculated half-lives in grape juice with those by Alberts et al. (2011). These authors studied pimaricin degradation in wine samples stored in standard wine bottles where artificial light had no effect on the rate of degradation, probably due to the absorption of the radiation by the glass. They reported half-lives for the degradation of pimaricin in wine of approximately 20 days at $20^{\circ} \mathrm{C}, 6$ days at $30^{\circ} \mathrm{C}$ and 2 days at $40{ }^{\circ} \mathrm{C}$.

When the pimaricin-treated juice was heated up to pasteurisation temperatures $\left(80^{\circ} \mathrm{C}\right)$ the pimaricin degradation was significantly increased (Fig. 3 ). The $k$ value was nearly 50 fold higher $(p=0.0021)$ at $80^{\circ} \mathrm{C}$ than at $25^{\circ} \mathrm{C}$. Consequently, the half-life was also reduced $(0.27 \mathrm{~h}$, Table 1$)$. On the other hand, there were no significant $(p=0.1110)$ differences between the $F_{\min }$ achieved in grape juice at 25 and $80^{\circ} \mathrm{C}$.

The results obtained show that pimaricin has a low stability under normal conditions (heating, acidification, lighting) for the production of fresh (non-sterilised) juices, which may potentially reduce its antimicrobial activity. This suggests that nanohydrogel-encapsulation may be a feasible procedure to protect pimaricin from degradation, and thus, to improve its antimicrobial activity.

\section{Dose-Response Assessment of Pimaricin: $\mathrm{IC}_{50}$}

Pimaricin is active in small quantities against almost all moulds and yeasts that cause food spoilage. Most moulds and yeast are sensitive to pimaricin concentrations lower than 10 and $3 \mathrm{ppm}$, respectively. The minimum inhibitorium concentration (MIC) for pimaricin varied from 0.5 to $2 \mathrm{ppm}$ for most species that can cause spoilage in beverages (Stark and Tan 2003). Koontz and Marcy (2003) reported MIC values against $S$. cerevisiae of $1.1 \pm 0.05 \mu \mathrm{g} \mathrm{mL}^{-1}$ in malt extract agar plates. However, the half maximal inhibitory concentration $\left(\mathrm{IC}_{50}\right)$ for pimaricin in YPD broth and grape juice against a food-spoilage microorganism has not been reported before. We performed a dose-response analysis to evaluate the effect of pimaricin on the growth of a food-spoilage indicator microorganism (S. cerevisiae).

The dose-response profiles obtained for each matrix are represented in Fig. 4. The $\mathrm{IC}_{50}$ for pimaricin in culture broth was $2.95 \pm 0.06 \mu \mathrm{g} \mathrm{mL}^{-1}$ and in grape juice $1.74 \pm$ $0.09 \mu \mathrm{g} \mathrm{mL}^{-1}$. It should be taken into account that even in the absence of pimaricin, the latency of $S$. cerevisiae in grape juice was 4.5 times higher than in culture broth. Grape juice is poorer in nitrogen and proteins, so the yeast growth in this medium might be limited by the absence of essential nutrients. This limitation should be strengthened in the presence of pimaricin that acts binding to ergosterol in membrane cells,

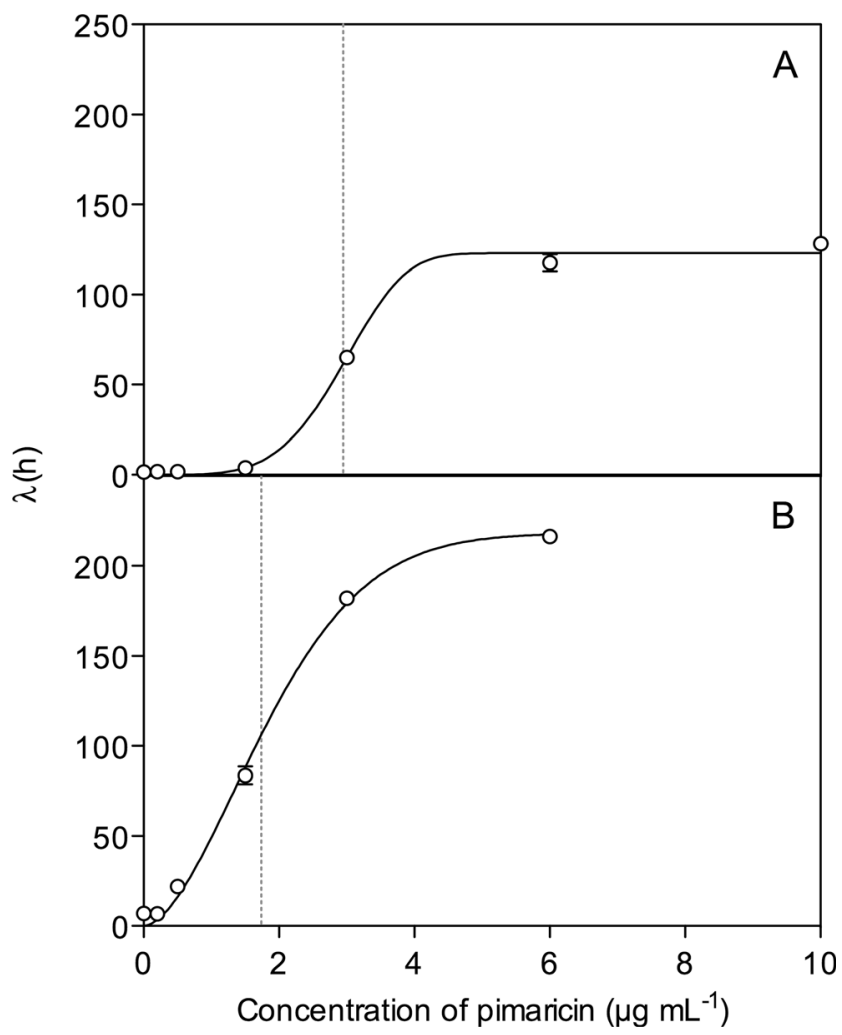

Fig. 4 Dose-response curves: latency of Saccharomyces cerevisiae cultures in YPD broth at $37^{\circ} \mathrm{C}$ (a) and in grape juice at $25^{\circ} \mathrm{C}(\mathbf{b})$, obtained in response to the exposure to increasing concentrations of pimaricin. The lines are the fitting curves generated from Eq. $3\left(r^{2}\right.$ YPD broth $\left(37^{\circ} \mathrm{C}\right)=0.9984 ; r^{2}$ grape juice $\left.\left(25^{\circ} \mathrm{C}\right)=0.9986\right)$. Dashed lines represent the $\mathrm{IC}_{50}$ calculated with Eq. 3 


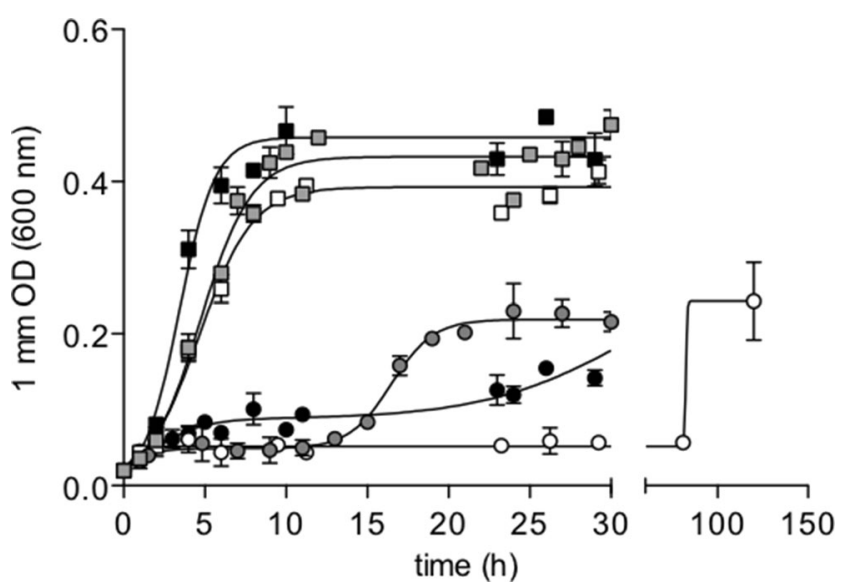

Fig. 5 Effect of different antimicrobial devices on Saccharomyces cerevisiae growth in a food model system (YPD broth). Treatments without pimaricin: $N_{\text {PNIPA(5) }}$ (black-filled square), $\mathrm{N}_{\text {PNIPA-20AA(5) }}$ (white-filled square) and $\mathrm{C}$ (grey-filled square). Treatments with pimaricin: $\mathrm{NP}_{\mathrm{PNIPA}(5)}$ (black-filled circle), $\mathrm{NP}_{\mathrm{PNIPA}-20 \mathrm{AA}(5)}$ (white-filled circle) and $\mathrm{P}$ (grey-filled circle). The line is the fitting curve generated from Eqs. 5 and 6

inhibiting relevant processes involved in cell regeneration (Te Welscher et al. 2008). Therefore, the absence of precursors for cellular regeneration can cause a further slowing down of the growth. Maximum inhibitions (i.e. higher latencies) were also higher in grape juice $(217 \mathrm{~h})$ than in YPD broth $(129 \mathrm{~h})$, meaning the antimicrobial capacity of pimaricin is much higher in grape juice than in culture broth.

Antimicrobial Activity of Pimaricin-Loaded PNIPA/AA Nanohydrogels in a Food Model System

We next tested the antifungal activity in the food model system when pimaricin was loaded in PNIPA/AA nanohydrogels. The experimental $S$. cerevisiae growth data (OD values) obtained were fitted with the reparameterised logistic model (Eq. 5) and reparameterised bilogistic model (Eq. 6) for series without and with antifungal treatment, respectively.
The results, illustrated in Fig. 5 and summarised in Table 2, show that pimaricin-loaded nanohydrogel was highly effective inhibiting the growth of the indicator strain. Treatments with pimaricin $\left(P, \mathrm{NP}_{\mathrm{PNIPA}(5)}\right.$ and $\left.\mathrm{NP}_{\mathrm{PNIPA}-20 \mathrm{AA}(5)}\right)$ led to a 2fold reduction $(p<0.05)$ in yeast growth compared to samples without pimaricin. Pimaricin-free nanohydrogels $\left(N_{\mathrm{PNIPA}(5)}\right.$ and $\left.N_{\text {PNIPA-20AA(5) }}\right)$ seem to have no negative effect on yeast growth as they showed no significant $(p>0.05)$ differences with control cultures (C) growth parameters, where no nanohydrogels was applied.

In addition, the combination of antifungal and nanohydrogel extended the latency of $S$. cerevisiae growth further than pimaricin alone (Table 2). The $\lambda_{B}$ was increased significantly $(p<0.05)$ from $12.39 \pm 0.54$ to $81.19 \pm 0.17 \mathrm{~h}$ in $\mathrm{P}$ and $\mathrm{NP}_{\mathrm{PNIPA}-20 \mathrm{AA}(5)}$ treatments, respectively.

Moreover, the advantage of using nanohydrogels with acrylic acid can be noted when comparing both inhibition curves. $\mathrm{NP}_{\mathrm{PNIPA}-20 \mathrm{AA}(5)}$ was able to stop $S$. cerevisiae growth completely in $81.19 \pm 0.17 \mathrm{~h}$, while $\mathrm{NP}_{\mathrm{PNIPA}(5)}$ only maintained the inhibition for $14.50 \pm 2.32 \mathrm{~h}$, after which exponential growth was observed. In addition, there were no significant $(p>0.05)$ differences between the $\lambda_{B}$ of samples treated with $P$ and $\mathrm{NP}_{\mathrm{PNIPA}(5)}$.

Ollé Resa et al. (2014) evaluated the antimicrobial activity of pimaricin against $S$. cerevisiae employing a whey protein concentrate solution as a model liquid food. They found that $20 \mathrm{ppm}$ of pimaricin reduced $S$. cerevisiae counts to 1.25 $\log \mathrm{CFU} \mathrm{mL} \mathrm{m}^{-1}$ after $96 \mathrm{~h}$ and maintained the antifungal effect during four additional days at $25{ }^{\circ} \mathrm{C}$. The lower temperature assayed $\left(25\right.$ vs. $\left.37^{\circ} \mathrm{C}\right)$ explains that the inhibition time $\left(\lambda_{B}\right)$ was higher than that obtained with free pimaricin treatment $(P)$. However, similar inhibition time $\left(\lambda_{B}\right)$ was obtained when pimaricin was released from PNIPA nanohydrogels copolymerized with AA ( $\left.\mathrm{NP}_{\mathrm{PNIPA}-20 \mathrm{AA}(5)}\right)$, despite being performed at a higher temperature that could increase pimaricin degradation and accelerate microbial growth.

These results are consistent with previous pimaricin release studies carried out in water Fuciños et al. (2014b), showing

Table 2 Growth parameters of Saccharomyces cerevisiae in culture broth under different antimicrobial treatments, calculated with Eqs. 5 and 6

\begin{tabular}{|c|c|c|c|c|c|c|c|}
\hline Treatment & $A$ & $v_{\max \mathrm{A}}\left(\mathrm{h}^{-1}\right)$ & $A_{0}$ & $B$ & $v_{\max B}\left(\mathrm{~h}^{-1}\right)$ & $\lambda_{B}(\mathrm{~h})$ & $r^{2}$ \\
\hline$C$ & - & - & - & $0.433 \pm 0.009 * * *$ & $0.069 \pm 0.008^{* * *}$ & $1.554 \pm 0.475^{* *}$ & 0.9731 \\
\hline$N_{\mathrm{PNIPA}(5)}$ & - & - & - & $0.458 \pm 0.015^{* * *}$ & $0.105 \pm 0.025^{* *}$ & $1.231 \pm 0.607^{\text {n.s. }}$ & 0.9631 \\
\hline$N_{\text {PNIPA-20AA }(5)}$ & - & - & - & $0.393 \pm 0.008^{* * *}$ & $0.059 \pm 0.007 * * *$ & $1.313 \pm 0.288^{*}$ & 0.9865 \\
\hline$P$ & $0.049 \pm 0.004 * * *$ & $0.015 \pm 0.009^{\text {n.s. }}$ & $0.019 \pm 0.007^{*}$ & $0.219 \pm 0.004 * * *$ & $0.033 \pm 0.004 * * *$ & $12.390 \pm 0.541 * * *$ & 0.9946 \\
\hline $\mathrm{NP}_{\mathrm{PNIPA}(5)}$ & $0.088 \pm 0.008^{* * *}$ & $0.014 \pm 0.005^{*}$ & $0.023 \pm 0.009^{*}$ & $0.292 \pm 0.009 * * *$ & $0.011 \pm 0.002 * * *$ & $14.500 \pm 2.230 * * *$ & 0.9856 \\
\hline $\mathrm{NP}_{\text {PNIPA-20AA(5) }}$ & $0.052 \pm 0.002 * * *$ & $0.035 \pm 0.022^{\text {n.s. }}$ & $0.020 \pm 0.008^{*}$ & $0.243 \pm 0.008 * * *$ & $0.117 \pm 0.272^{\text {n.s. }}$ & $81.191 \pm 0.167 * * *$ & 0.9860 \\
\hline
\end{tabular}

Values reported are the means \pm standard deviation $(n=2)$

n.s. not significant $(p>0.05)$

${ }^{*} p<0.05$, significant, ${ }^{* *} p<0.01$, very significant, ${ }^{* * *} p<0.001$, extremely significant 


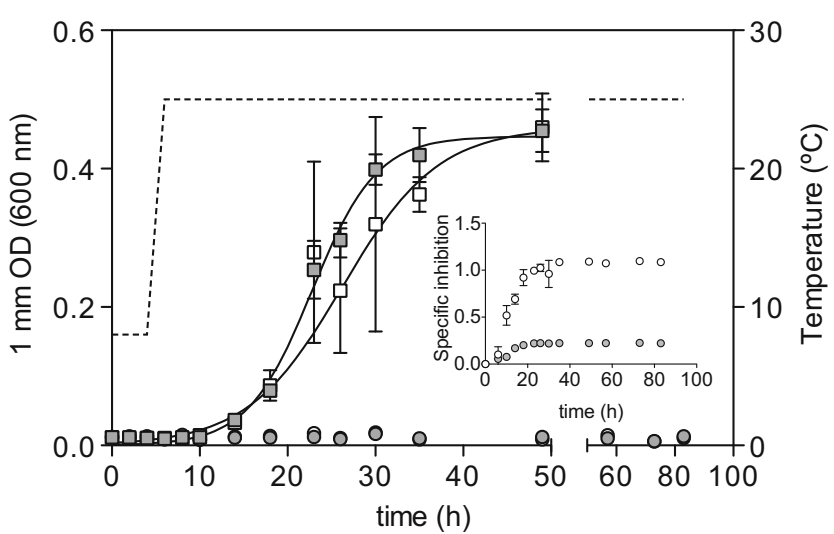

Fig. 6 Effect of different antimicrobial devices on Saccharomyces cerevisiae growth in grape juice. Control samples without pimaricin: $\mathrm{N}_{\text {PNIPA-20AA(5) }}$ (white-filled square) and C (grey-filled square). Samples

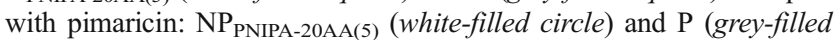
circle). The line is the fitting curve generated from Eq. 5. The dashed line shows the temperature cycling of the release media between 37 and $15^{\circ} \mathrm{C}$. The figure inset represents the specific inhibition at different times

PNIPA nanohydrogels copolymerized with AA allowing for a slower but sustained release of pimaricin. This system allows for maintaining high pimaricin levels able to control yeast growth.

\section{Antimicrobial Activity of Pimaricin-Loaded PNIPA/AA Nanohydrogels in a Real Food: Grape Juice}

In view of the good results in liquid food model system (Sect. 3.3), in the study of antimicrobial activity of pimaricin-loaded PNIPA/AA nanohydrogels was evaluated with PNIPA-20AA(5) nanohydrogels as an alternative to traditional treatments, which consists of free pimaricin directly added to food bulk.

Figure 6 compares of the effect on yeast growth of pimaricin treatments directly added to a grape juice or included in the nanohydrogel. Treatments without pimaricin $(C$ and $\left.N_{\text {PNIPA-20AA(5) }}\right)$ seem to have no effect on $S$. cerevisiae growth in contrast to pimaricin treatments ( $P$ and $\left.\mathrm{NP}_{\mathrm{PNIPA}-20 \mathrm{AA}(5)}\right)$. Table 3 shows the growth parameters of $S$. cerevisiae in the presence of different treatments, after fitting the experimental growth data to Eq. 5 .

There were no significant $(p>0.05)$ differences between $S$. cerevisiae growth parameters (Table 3 ) of treatments without pimaricin $\left(C\right.$ and $\left.N_{\mathrm{PNIPA}-20 \mathrm{AA}(5)}\right)$. The pimaricin treatments $\left(P\right.$ and $\left.\mathrm{NP}_{\mathrm{PNIPA}-20 \mathrm{AA}(5)}\right)$ completely inhibit the growth of $S$. cerevisiae (Fig. 6). These results confirm those obtained in the liquid food model system (Sect. 3.3) where the nanohydrogel did not interfere with $S$. cerevisiae growth.

Fuciños et al. (2014b) proposed an equation to calculate the pimaricin released from nanohydrogels at different $\mathrm{pH}$ and temperature conditions. So, the maximum concentration of pimaricin released during the entire experiment, under the grape juice storage conditions used (see Sect. 2.4.4), would be equal to $0.90 \pm 0.0002 \mu \mathrm{g} \mathrm{mL}^{-1}$. This concentration is significantly lower $(p<0.05)$ than the $\mathrm{IC}_{50}$ calculated in Sect. 3.2 for free pimaricin in grape juice $\left(1.74 \pm 0.09 \mu \mathrm{g} \mathrm{mL}^{-1}\right)$. Therefore, the nanohydrogel acts protecting pimaricin from degradation providing a more effective inhibition. So specific inhibition was calculated by applying Eq. 4 .

The inset in Fig. 6 represents the specific inhibition of $S$. cerevisiae with $P$ and NP treatments, showing that the specific inhibition with the $\mathrm{NP}_{\mathrm{PNIPA}-20 \mathrm{AA}(5)}$ treatment is clearly higher than that of the $P$ treatment.

\section{Conclusions}

This work demonstrates the usefulness of pimaricin-loaded nanohydrogel devices to control the microbial spoilage of grape juice, providing an effective inhibition of yeast growth due to the combination of two mechanisms: slow and controlled release of pimaricin and protection against environmental degradation of the antifungal compound. These release devices also reduced the pimaricin concentration in the juice but while still obtaining a yeast inhibitory effect.

These results demonstrate the possibility of using pimaricin-loaded nanohydrogels in active packaging by their incorporation in food contact materials in order to extend the shelf life of refrigerated and pasteurised foods once the packaging has been opened.

Table 3 Growth parameters of Saccharomyces cerevisiae in grape juice under different antimicrobial treatments, calculated with Eq. 5

\begin{tabular}{lllll}
\hline Treatment & $B$ & $v_{\operatorname{max~B}}\left(\mathrm{h}^{-1}\right)$ & $\lambda_{B}(\mathrm{~h})$ & $r^{2}$ \\
\hline$C$ & $0.447 \pm 0.011^{* * *}$ & $0.030 \pm 0.002^{* * *}$ & $15.440 \pm 0.628^{* * *}$ & 0.9886 \\
$N_{\text {PNIPA-20AA(5) }}$ & $0.460 \pm 0.032^{* * *}$ & $0.021 \pm 0.003^{* * *}$ & $15.381 \pm 1.770^{* * *}$ & 0.9415 \\
$P$ & - & - & - & - \\
$\mathrm{NP}_{\text {PNIPA-20AA(5) }}$ & - & - & - & - \\
\hline
\end{tabular}

Values reported are the means \pm standard deviation $(n=2)$

$* * * p<0.001$, extremely significant 
Acknowledgements This work was funded by grant (MAT 200611662-CO3-CO2-C01/MAT 2010-21509-C03-01/EUI 2008-00115) from the "Ministerio de Educación y Ciencia" (Spain). Clara Fuciños gratefully acknowledges her Postdoctoral grant (SFRH/BPD/87910/ 2012) from the Fundação para a Ciência e Tecnologia (FCT, Portugal). Pablo Fuciños gratefully acknowledges his Marie Curie COFUND Postdoctoral Research Fellow.

\section{References}

Alberts, P., Stander, M. A., \& de Villiers, A. (2011). Development of a fast, sensitive and robust LC-MS/MS method for the analysis of natamycin in wine. South African Journal for Enology and Viticulture, 32(1), 51-59.

Bozkurt, H., \& Erkmen, O. (2001). Predictive modeling of Yersinia enterocolitica inactivation in Turkish Feta cheese during storage. Journal of Food Engineering, 47(2), 81-87.

Brody, A. L., Bugusu, B., Han, J. H., Sand, C. K., \& McHugh, T. H. (2008). Innovative food packaging solutions. Journal of Food Science, 73(8), R107-R116.

Dai, Y., McLandsborough, L. A., Weiss, J., \& Peleg, M. (2010). Concentration and application order effects of sodium benzoate and eugenol mixtures on the growth inhibition of Saccharomyces cerevisiae and Zygosaccharomyces bailii. Journal of Food Science, 75(7), M482-M488.

Dainelli, D., Gontard, N., Spyropoulos, D., Zondervan-van den Beuken, E., \& Tobback, P. (2008). Active and intelligent food packaging: legal aspects and safety concerns. Trends in Food Science and Technology, 19(SUPPL. 1), S99-S108.

Dalgaard, P., \& Koutsoumanis, K. (2001). Comparison of maximum specific growth rates and lag times estimated from absorbance and viable count data by different mathematical models. Journal of Microbiological Methods, 43(3), 183-196.

Eeckman, F., Moës, A. J., \& Amighi, K. (2004). Poly(Nisopropylacrylamide) copolymers for constant temperature controlled drug delivery. International Journal of Pharmaceutics, 273(1-2), 109-119.

Farid, M. A., El-Enshasy, H. A., El-Diwany, A. I., \& El-Sayed, E. A. (2000). Optimization of the cultivation medium for natamycin production by Streptomyces natalensis. Journal of Basic Microbiology, 40(3), 157-166.

Fuciños, C., Guerra, N. P., Teijón, J. M., Pastrana, L. M., Rúa, M. L., \& Katime, I. (2012). Use of poly( $N$-isopropylacrylamide) nanohydrogels for the controlled release of pimaricin in active packaging. Journal of Food Science, 77(7), N21-N28.

Fuciños, C., Fuciños, P., Míguez, M., Katime, I., Pastrana, L. M., \& Rúa, M. L. (2014a). Temperature- and pH-sensitive nanohydrogels of poly( $N$-isopropylacrylamide) for food packaging applications: modelling the swelling-collapse behaviour. PLoS ONE, 9(2), e87190.

Fuciños, C., Fuciños, P., Pastrana, L. M., \& Rúa, M. L. (2014b). Functional characterization of poly ( $N$-isopropylacrylamide) nanohydrogels for the controlled release of food preservatives. Food and Bioprocess Technology. doi:10.1007/s11947-014-1351-5.

Guerra, N. P., Fajardo, P., Fuciños, C., Amado, I. R., Alonso, E., Torrado, A., \& Pastrana, L. (2010). Modelling the biphasic growth and product formation by Enterococcus faecium CECT 410 in realkalized fed-batch fermentations in whey. Journal of Biomedicine and Biotechnology. art. no. 290286.
Koontz, J. L., \& Marcy, J. E. (2003). Formation of natamycin:cyclodextrin inclusion complexes and their characterization. Journal of Agricultural and Food Chemistry, 51(24), 7106-7110.

Koontz, J. L., Marcy, J. E., Barbeau, W. E., \& Duncan, S. E. (2003). Stability of natamycin and its cyclodextrin inclusion complexes in aqueous solution. Journal of Agricultural and Food Chemistry, 51(24), 7111-7114.

Manalili, N. M., Dorado, M. A., \& van Otterdijk, R. (2011). Appropriate food packaging solutions for developing countries. In: Save food! Interpack2011. FAO, pp. 1-28.

Murado, M. A., González, M. P., \& Vázquez, J. A. (2002). Dose-response relationships: an overview, a generative model and its application to the verification of descriptive models. Enzyme and Microbial Technology, 31(4), 439-455.

Ollé Resa, C. P., Jagus, R. J., \& Gerschenson, L. N. (2014). Natamycin efficiency for controlling yeast growth in models systems and on cheese surfaces. Food Control, 35, 101-108.

Pedersen, J. C. (1992). Natamycin as a fungicide in agar media. Applied and Environmental Microbiology, 58(3), 1064-1066.

Roberts, D. P. T., Scotter, M. J., Godula, M., Dickinson, M., \& Charlton, A. J. (2011). Development and validation of a rapid method for the determination of natamycin in wine by high-performance liquid chromatography coupled to high resolution mass spectrometry. Analytical Methods, 3(4), 937-943.

Sekhon, B. S. (2010). Food nanotechnology-an overview. Nanotechnology, Science and Applications, 3, 1-15.

Stark, J., \& Tan, H. S. (2003). Natamycin. In N. J. Russell \& G. W. Gould (Eds.), Food preservatives (pp. 179-195). New York, USA: Kluwer Academic/Plenum Publishers.

Te Welscher, Y. M., Ten Napel, H. H., Balagué, M. M., Souza, C. M., Riezman, H., De Kruijff, B., \& Breukink, E. (2008). Natamycin blocks fungal growth by binding specifically to ergosterol without permeabilizing the membrane. Journal of Biological Chemistry, 283(10), 6393-6401.

Vally, H., \& Misso, N. L. (2012). Adverse reactions to the sulphite additives. Gastroenterology and Hepatology from Bed to Bench, 5(1), 16-23.

Vanden Bossche, H., Engelen, M., \& Rochette, F. (2003). Antifungal agents of use in animal health - chemical, biochemical and pharmacological aspects. Journal of Veterinary Pharmacology and Therapeutics, 26(1), 5-29.

Vázquez, J. A., \& Murado, M. A. (2008). Mathematical tools for objective comparison of microbial cultures. Application to evaluation of 15 peptones for lactic acid bacteria productions. Biochemical Engineering Journal, 39(2), 276-287.

Vázquez, J. A., Docasal, S. F., Prieto, M. A., González, M. P., \& Murado, M. A. (2008). Growth and metabolic features of lactic acid bacteria in media with hydrolysed fish viscera. An approach to bio-silage of fishing by-products. Bioresource Technology, 99(14), 6246-6257.

Wachenheim, D. E., Patterson, J. A., \& Ladisch, M. R. (2003). Analysis of the logistic function model: derivation and applications specific to batch cultured microorganisms. Bioresource Technology, 86(2), $157-164$.

Zhang, X., Zhuo, R., Cui, J., \& Zhang, J. (2002). A novel thermoresponsive drug delivery system with positive controlled release. International Journal of Pharmaceutics, 235(1-2), 43-50.

Zwietering, M. H., Jongenburger, I., Rombouts, F. M., \& Van't Riet, K. (1990). Modeling of the bacterial growth curve. Applied and Environmental Microbiology, 56(6), 1875-1881. 